mation following the injection, and how Dr. Kiliani explained the relief that followed the procedure. Any radical method of affecting a peripheral nerve that was catusing repeated attaeks of intense pain, either of a spasmodic or a continuous nature, must either cause a degeneration of its nerve fibers, which was distinctly an interstitial ehange, or eause an accumulation of leucocytes in the neighborhood of the ncrve trunk, either as an inflammatory reaction, as in counter irritation, and so reduee any peri-netritis or netritis proper.

Dr. Kiliani said he had no explanation to offer as to the effect of these alcohol injections. As a matter of faet, nobody knew what neuralgia was or what produced it, and even eareful microscopic examinations had failed to reveal any changes in the involved nerve. It eould be safely assumed, however, that the injcetions of alcohol produeed a eertain amount of paresis of the nerve, and during the course of the injection the patient deseribed the gradual numbness following the distribution of the nerve. This numbness disappeared in the course of a few days or wceks, but there was no return of the pain. Ncuralgia patients were eured by the alcohol injections, inasmuch as the pain disappeared entirely, but a number of cases showed a reeurrenee after about a year, when a few further injections completed the cure. The operation is so small and connected with so little inconvenience, that the patients are quite willing to undergo the treatment again if neeessary.

\title{
VOICE RECORDS IN NERVOUS AND MENTAL DISEASES.
}

$$
\text { By Dr. E. W. Seripturc. }
$$

A method of rccording the voice by a very small capsulc was demonstrated, and reeords of voiecs in general paresis, hysteria, paralysis agitans, hemiplegia and epilepsy were comparcd with normal voice reeords. In these reeords, the vowels appcared as small waves on a line whose height indicated the rate of expulsion of brcath. The regulation of the breath in general paresis was seen to be very irrcgular, while in hysteria it was crratie.

Curves of oeelusives and fricatives were shown. The irrcgular and uneertain regulation of breath and muscular action were evident here also in general paresis. The faintncss of breath aetion in paralysis agitans was noted. The duration of the sounds was often greatly prolonged in paresis and multiple selerosis. The melody of speceh was obtained by measuring the littlc wavcs, eaeh singly. The nelody of speech in general paresis showed exeessive fluetuation. The peeuliar monotony in epileptic voices was so marked that it could bc regarded as a regular symptom of the disease. The senile tremolo in melody at the bcginning of vowels was shown.

Dr. George H. Kirby said that while attending Professor Kraepclin's clinic at Munich last summer, he had an opportunity to do some work with the methods developed by Dr. Scripture for the study of speech defeets and voiee alterations. Among the patients upon whom the experiments were made there wcre some with general paresis in whom one could not find any speech defeet by the ordinary tests, yet when the speeeh curves were studied one eould elearly detcct an alteration in the vibrations from the vowels, and peeuliar fluetuations in the melody not observed in normal persons. These characteristies were quite clear in the records, but could not be detected otherwise, at least not by the untrained ear. The method thus might become really of practieal value and 
a diagnostic aid. In one patient with pupillary signs and a speech defect the diagnosis was between general paralysis and a hysterical psychosis. The record obtained from this patient showed peculiarities entirely different from those obtained from the general paralytics. The further observation, as well as the anamnesis, made it clear that the case was really one of hysteria.

Dr. L. Pierce Clark said that Dr. Scripture, for a number of years, had maintained that the voice of the epileptic was as characteristic as the facies, or more so, and that he had been induced to undertake with him a careful analysis of the voice in epilepsy. They had found that particularly in the grand mal type the voice of the epileptic showed certain alterations which were quite as characteristic as any of the well recognized stigmata of epilepsy. In order to test the accuracy of these observations on the voice in epilepsy, a number of patients at Randall's Island who were subject to that disease were nixed up with others who were suffering from various grades of mental deficiency about on a par with those usually observed in the chronic epileptic, and in nine of these patients out of ten, Dr. Scripture was able to detect merely from the speech whether the case was one of epilepsy or not.

Dr. Clark said that these voice studies seemed to him of immense scientific as well as practical value. For instance, it may be possible in the near future to roughly record in ordinary case-taking the melody, pitch and rhythm curves of speech in various functional nervous disorders, such as those of epilepsy, hysteria, netrasthenia and the like neuroses.

Dr. Onuf asked Dr. Scripture whether in epilepsy he could make the diagnosis from the voice alone, or whether he required the voice record, and what was his interpretation of the latter.

Dr. Scripture replied that while the existence of epilepsy could be recognized, after a little training, from the voice alone, he always preferred to base his opinion on the actual voice records and curves, when possible. When these were once heard and recognized, they were distinct and characteristic. The characteristic voice disappeared after the epilepsy was cured.

Dr. Leszynsky asked whether these characteristic voice curves were present in epilepsy of the ordinary type.

Dr. Dana asked how long after the onset of epilepsy this characteristic voice developed.

Dr. Clark said these questions could not be answered definitely, as the studies were only begun. The cases that had been studied were of the chronic type of epilepsy-patients in whom the disease had existed for periods ranging from two to ten years. The method had not yet been tried at the Craig Colony. He expressed the view that these characteristic voice curves would become as constant and fixed as other symptoms of the disease.

Dr. Scripture said the voice characteristics were apparent in the measurements of the curves long before they could be detected by the ear.

\section{DISCUSSION ON THE ANTI-SYPHILITIC TREATMENT OF TABES AND PARESIS.}

Dr. Dana said he had been treating these forms of nervous disease for many years by the use of mercury and iodides in the early stages, 